\title{
Quantifying the Community Effect on Contraceptive Use in Egypt
}

\begin{abstract}
By Noura Anwar
Egypt has significant regional heterogeneity in contraceptive use rates. Few previous studies showed that the regional variation remains even after controlling for individual and household characteristics. This study aims at investigating the multilevel dependence of contraceptive use on socioeconomic change in Egypt between 2000 and 2014. The questions of this research are: 1) Do the regional variations in contraceptive use change with time? 2) To what extent can the regional variations be explained in terms of individual, household and contextual variables? Egypt Demographic and Health surveys "EDHS"; 2000 and 2014, are the main sources of data. EDHS is a nationally representative survey, it provides data of (15-49) ever-married women. For specifying the individual and contextual determinants of Contraceptive use, the multilevel modelling approach is used. The dependent variable is "the current use of any modern method"; this variable is a dichotomous variable; it equals 1 , if the woman is currently using any modern method and it equals 0 , if she isn't using. The results show that about $7.5 \%$ of the variability in the current use of any modern method is due to the differences between level 1 units (governorates of Egypt) in 2000. This percentage decreased to reach 6.6\% in 2014. This indicates that still the contraceptive use rates depends on the socioeconomic development and the contextual norms heterogeneity among different regions of Egypt. The level of education of woman and her husband, her discussion of family planning and her husband's approval on family planning, on the womenlevel, the mean number of children ever born and wealth index, on the regionslevel are the most important variables affecting the odds of using a modern contraceptive method.
\end{abstract}

Keywords: Multilevel Models, Contextual Effects, Contraceptive Use, Determinants, Egypt.

\section{Introduction}

Egypt has significant regional heterogeneity in contraceptive use rates. Previous studies showed that the regional variation still exists even after controlling for individual and household characteristics (Guisti and Vignoli 2006).

Contraception is the most effective proximate determinant of fertility according to the framework of Bongaarts in 1982 and his further work in 1984. In addition to the direct effect of contraception on fertility, it has great health outcomes on maternal and child health through decreasing maternal mortality rates and preventing many maternal morbidities (Aizenman 1988, Stover and Ross 2009, Ahmed et al. 2012)

\footnotetext{
*Assistant Professor, Department of Biostatistics and Demography, Institute of Statistical Studies and Research, Cairo University, Egypt.
} 
Egypt has one of the most successful family planning programs, it has achieved great success in this field within 20 years since the contraceptive use rate increased from about 38\% in 1988 to about 60\% in 2008 (Sayed et al. 1988, Elzanaty and Way 2008). In spite of the continuous efforts of the family planning program in Egypt, the contraceptive use rate has witnessed a frustrating plateau during 2005 and 2008; to about 60\%, and it has slightly decreased in 2014 to 59\% (Elzanaty and Way 2005, 2008, Ministry of Health and Population 2015, Rashad and Zaky 2013). The stagnation in the prevalence rate of contraceptives during the nineties and the slight decrease experienced during 2008 and 2014 should be investigated through identifying both the individual and contextual determinants of contraceptive use.

In an attempt to inform the Egyptian family planning program and population-related decision making processes in Egypt, this study aims at tracking the change in the combination of factors affecting the contraceptive use rate in Egypt between 2000 and 2014, this may be achieved through; first, measuring the community effect on the probability of using any modern contraceptive method. Second, studying women-level and contextual-level factors that are influencing the odds of contraceptive use.

Specifically, the research questions are: 1) Do the regional variations in contraceptive use change with time? 2) To what extent can the regional variations be explained in terms of individual, household and contextual variables?

\section{Literature Review}

Worldwide, many previous researches studied the determinants of contraceptive use. Most of them focused on analyzing the probability of using any method for family planning on the individual level only; i.e. identifying individual and household characteristics that act as determinants of contraceptive use. While other researchers showed that contraceptive use is influenced by two sets of variables; the first set reflects women-level characteristics and the other set reflects context-level characteristics.

As for women's individual and household characteristics that have been identified through many studies to significantly affect the probability of using any effective method for family planning, there exist certain women's demographic characteristics such as; age of woman and her parity. Also, there are some women's socioeconomic characteristics, of them: woman's educational level, type of current place of residence, type of birth place of residence, her level of empowerment and autonomy, working status and type of occupation (especially whether she is working in governmental or private sector). This is in addition to other factors such as; her exposure to family planning messages through mass media and her attitudes towards family planning. This is along with her husband's characteristics. (Al Riyami et al. 2004, Awadalla 2012, Ragab and AbdelWahid 2014, Moursund and Kravdal 2003, Osmani et al. 2015, El-Moselhy et al. 2017, Samari 2017). 
On the other hand, there are many context-level variables affects women's behavior towards contraception, of them, the level of socioeconomic development of the region, level of school participation, economic roles of children which may be highly associated with the dominant economic activity; industrial, Agricultural, commercial, ...etc., level of women autonomy, female labor force participation rates, the number of family health units in her place of residence, community fertility norms, doctor staffing levels, number of community health workers and number of well trained nurses (Entwisle et al. 1986, Moursund and Kravdal 2003, Stephenson et al. 2007 and 2008, Ahmed et al. 2012, Elfstrom and Stephenson 2012, Longwe et al. 2012, Eltomy et al. 2013, Lamidi 2015, Sedgh et al. 2016).

In Egypt, most of previous studies investigated the determinants of contraceptive use on the individual and household level. In almost all of these studies there was a consensus on that the probability of using family planning methods is higher among older, high parity women, better-educated women, working women, women residing in urban places (Mahran et al. 1995, Awadalla 2012, Ragab and AbdelWahid 2014, El-Moselhy et al. 2017).

Very few researchers explored the contextual influence on contraceptive use in Egypt. In 2006, Guisti and Vignoli studied the determinants of the ever-use of contraception in Egypt using a multilevel approach with a special reference to the differentials due to the socio-economic context and the type of place of residence. The key finding of their research was that the individual characteristics of the woman, especially those related to husband and the economic class of her community explained part of the unobserved heterogeneity that exist between the different communities of Egypt.

\section{Methodology}

The current study is interested in studying the determinants of using any modern contraceptive method, since these methods are the most effective path for controlling the level of fertility. Egypt Demographic and Health surveys "EDHS"; 2000 and 2014, are the main sources of data. EDHS is a nationally representative survey, it provides data of (15 - 49) ever-married women. It provides data of many indicators covering many demographic and reproductive health dimensions such as fertility, contraceptive use, infant and child health and mortality, coverage of antenatal and delivery care, nutrition of mother and child, some anthropometric measures and prevalence of anemia. Meanwhile it provides also many background and socioeconomic characteristics of women, husbands and households.

For measuring the community effect on the probability of contraceptive use and specifying the significant determinants of Contraceptive use, multilevel modelling approach is to be used. The analysis focus on currently married women aged (15-49), not pregnant and want no more children (either for spacing or limiting). The number of women in this group is 8396 women in 2000 and 10809 women in 2014. 
The dependent variable is the current use of any modern method. This variable is a dichotomous variable, it equals 1 , if the woman is currently using any modern method and it equals 0 , if she isn't using.

To achieve study objectives, the analysis is divided into a series of consecutive models:

- A binary-logistic two level null model with random intercept, in order to assess the community effect on contraceptive use on both years; 2000 and 2014.

- A binary-logistic two level random intercept model with individual characteristics (on lower level), in order to identify the determinants of contraceptive on the individual level and the volume of variability explained by them and the change of the effect of some variables between 2000 and 2014 are highlighted.

- A binary-logistic two level random intercept model with contextual variables (on higher level), in order to identify the contextual determinants of contraceptive and the volume of variability explained by them and the change of the effect of some variables between 2000 and 2014 are highlighted as well.

In what follows is the general form of the two level binary logistic regression model, equation 1 presents the logistic link function, which is the most appropriate in this case. It is used to link between the log - odds of success (according to the outcome variable, the success occurs when a woman use any modern contraceptive method) on the left hand side and a linear combination of explanatory variables on the right hand side (Hox et al. 2017). We can notice that equation 1 doesn't include an error term, this is because the underlying probability distribution associated with the outcome variable $Y_{i j}$ is not normally distributed (Raudenbush and Bryk 2002). Equation 2 presents a generic structural model of level-2. At level-2, the level-1 coefficients $\beta_{q j}$ become outcome variables modeled in terms of a linear combination of level- 2 explanatory variables.

$$
\begin{aligned}
& \log \left[\frac{\pi_{i j}}{1-\pi_{i j}}\right]=\beta_{0 j}+\beta_{1 j} X_{1 i j}+\beta_{2 j} X_{2 i j}+\cdots+\beta_{q j} X_{q i j} \\
& \beta_{q j}=\gamma_{q 0}+\gamma_{q 1} W_{1 j}+\gamma_{q 2} W_{2 j}+\cdots+\gamma_{q S_{q}} W_{S_{q j}}+u_{q j} .
\end{aligned}
$$

Where

$\pi_{i j}=$ the probability of success,

$X_{q i j}=$ level-1 predictors,

$\beta_{q j}=$ level-1 coefficients,

$W_{S_{q} j}=$ level-2 predictors,

$\gamma_{q s_{q}}=$ level- 2 coefficients, and $u_{q j}=$ level- 2 random effects. 


\section{Results}

Contraceptive Use in Egypt: Trends and Patterns among Regions Since 1988

This subsection will present a descriptive analysis of rates of contraceptive use of any modern method among currently married women since 1988 until 2014 and its pattern of distribution among regions of Egypt.

Figure 1. Trend of Current Use of Contraception among Currently Married Women 1988 - 2014

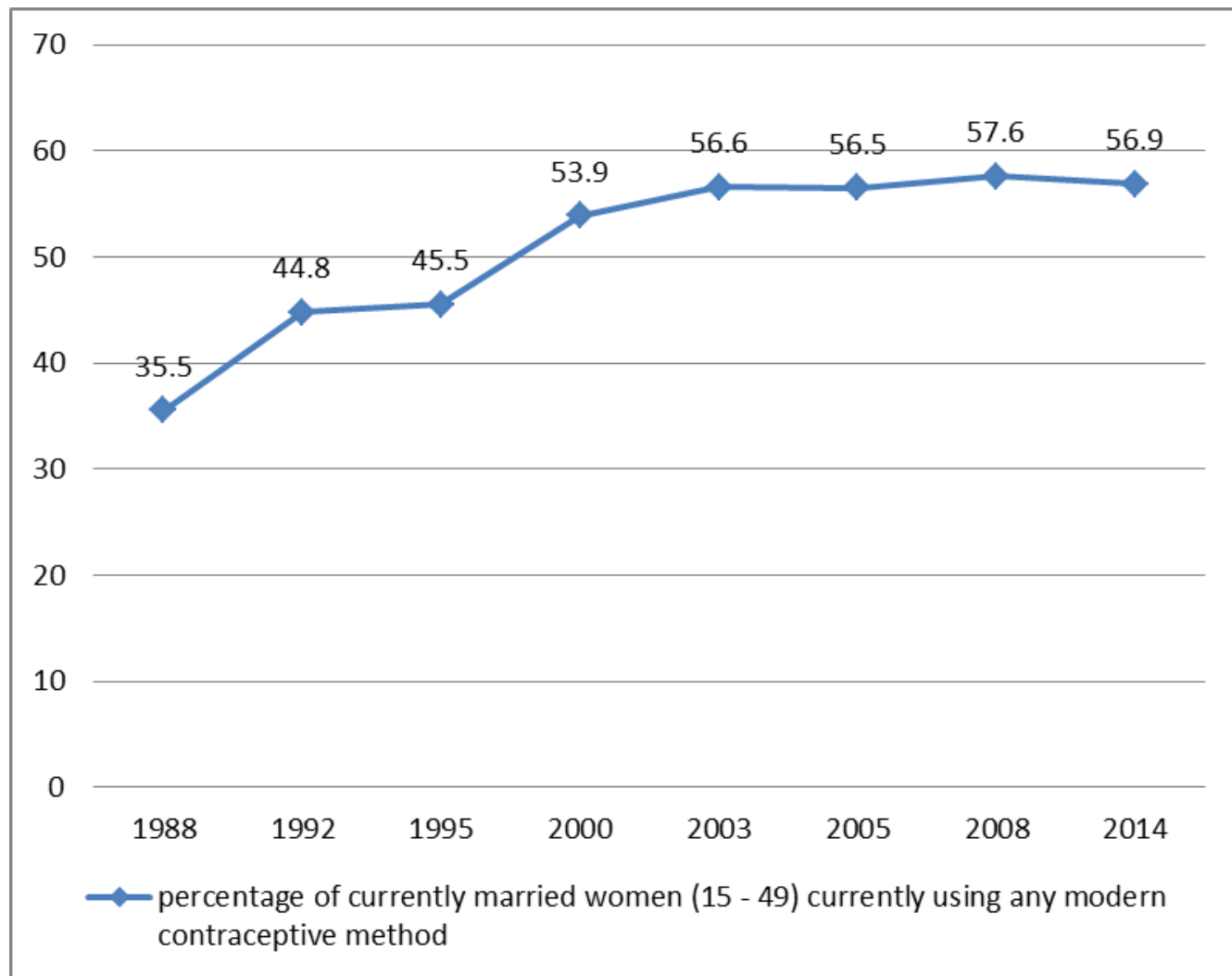

Source: By researcher depending on EDHS reports 1988, 1992, 2000, 2003, 2005, 2008 and 2014.

The percentage of currently married women using any modern contraceptive method increases considerably with time between 1988 and 2003. Further, from 2003 until 2014, modern contraceptives prevalence exhibits a stagnation, with a slight decrease in 2014 (see Figure 1).

The distribution of current use of any modern contraceptive method is different among regions of Egypt. Rural Upper Egypt is the most disadvantaged among others with least prevalence of modern methods over the whole time span. It should be noted that Rural Lower Egypt achieved highest rates of prevalence among others in 2014 (see Figure 2). 
Figure 2. Pattern of current use of contraception among regions of Egypt 19952014

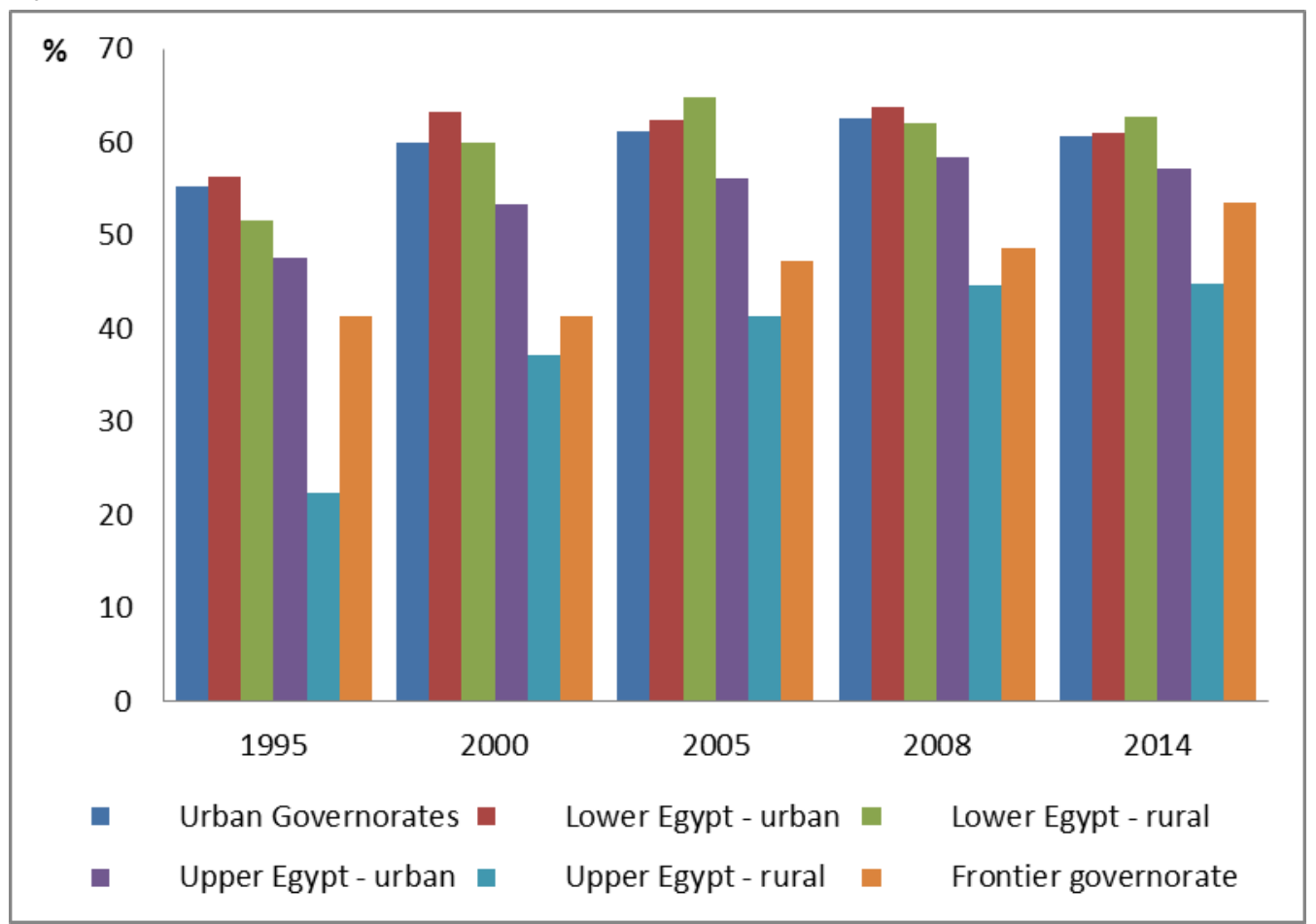

Source: By researcher depending on The DHS Program STATcompiler - http://www.statcom piler.com -April 2019.

Form the above analysis, the need for exploring the community effect on contraceptive use is justified and it will be shown in the following subsections.

Multilevel Approach for Analyzing the Determinants of Contraceptive Use

The Null Model for Quantifying the Community Effect on the Odds of Using Any Modern Contraceptive Method in 2000 and 2014

The basic purpose of multilevel modeling is the investigation of randomly varying outcomes (i.e., intercepts and slopes) across groups. So that, we will begin with quantifying the volume of the community effect on the odds of using a modern contraceptive method. This is done by fitting a null (empty) two-level model, which is a model with only an intercept and community effects.

$$
\log \left[\frac{p_{i j}}{1-p_{i j}}\right]=\beta_{0}+u_{0 j}
$$

The intercept $\beta_{0}$ is shared by all communities while the random effect $u_{0 j}$ is specific to community $\mathrm{j}$. The random effect is assumed to follow a normal distribution with mean equals zero and variance $\sigma_{u 0}^{2}$. 
After fitting the null model to 2000 and 2014 data, the results suggest that a woman is about 2.1 times more likely to use a modern contraceptive method than not using in an average community (where $U_{0 j}=0$ ) in 2000, since the intercept equals 0.763 , while in 2014, a woman is about 3 times more likely to use a modern contraceptive method than not using in an average community, since the intercept equals 1.135. And the variance of $u_{0 j}$ is estimated as $\sigma_{u 0}^{2}=0.267$ in 2000 and 0.231 in 2014 , and both of them are statistically significant at 0.05 level of significance.

The results also show that the ICC $=7.5$ in 2000 and 6.6 in 2014. which indicates that around $7.5 \%$ of the variability in the log odds of using a modern contraceptive method is due to the differences between communities (higher level units) in 2000, and this effect decreased in 2014 to reach to $6.6 \%$.

\section{Models with Level-1 Predictors and Random Intercept in 2000 and 2014}

In this subsection, we concentrate only on presenting the results of an intermediate stage of the analysis, models with level-1 predictors and random intercept of 2000 and 2014. The importance of this stage of analysis stems from its ability to answer the following question: after controlling the effect of the most important woman- level determinants, what is the volume of unexplained variability in the odds of using any modern contraceptive method on the regional level?

Table 1. Variance of the Random Intercept and the Intra-Class Correlation for the Null Model and the Model with Level-1 Predictors

\begin{tabular}{|l|c|c|c|c|}
\hline \multirow{2}{*}{} & \multicolumn{2}{|c|}{2000} & \multicolumn{2}{c|}{2014} \\
\cline { 2 - 5 } & Null model & $\begin{array}{c}\text { Model with level-1 } \\
\text { predictors }\end{array}$ & $\begin{array}{c}\text { Null } \\
\text { model }\end{array}$ & $\begin{array}{c}\text { Model with level-1 } \\
\text { predictors }\end{array}$ \\
\hline $\begin{array}{l}\text { Second } \\
\text { level } \\
\text { variance }\end{array}$ & 0.267 & 0.173 & 0.231 & 0.177 \\
\hline ICC & 7.5 & 4.9 & 6.6 & 5.1 \\
\hline
\end{tabular}

From Table 1, we can answer the previous question. It is obvious that after considering the most important woman - level predictors (number of children ever born, difference in age between spouses, the educational level of woman and her husband, the attitudes of husband towards family planning, and the discussion between spouses on family planning), the regional effect on the odds of using any modern contraceptive method reduced by $35.6 \%$ in 2000 and $22.7 \%$ in 2014 .

The ICC also indicates that still there are a considerable amount of unexplained regional effect on the dependent variable still needs to be explained. The rest of variability in the outcome that lies between groups will be explained through the following models which will include a set of contextual predictors. 
Models with Level-1 Predictors, Contextual Predictors and Random Intercept in 2000 and 2014

In this subsection, we consider the results of the two final models, in which the individual and contextual determinants of modern contraceptive use are added to the null model. The results are shown in Table 2.

Table 2. Women-Level and Contextual Determinants of Modern Contarceptive Use in Egypt, 2000 and 2014

\begin{tabular}{|c|c|c|c|c|}
\hline \multirow{2}{*}{$\begin{array}{l}\text { Year } \\
\text { Predictors }\end{array}$} & \multicolumn{2}{|c|}{2000} & \multicolumn{2}{|l|}{2014} \\
\hline & $\operatorname{Exp}(\beta)$ & Sig & $\operatorname{Exp}(\beta)$ & Sig \\
\hline \multicolumn{5}{|l|}{ Fixed Effects } \\
\hline \multicolumn{5}{|l|}{ Women - level variables } \\
\hline Intercept & 0.622 & 0.013 & 1.132 & 0.000 \\
\hline $\begin{array}{l}\text { Number of children ever born } \\
\text { (centered) }\end{array}$ & 0.930 & 0.000 & 0.943 & 0.001 \\
\hline Age difference between spouses & 0.985 & 0.001 & 0.984 & 0.000 \\
\hline $\begin{array}{l}\text { Woman's educational level (ref. } \\
\text { lower levels) }\end{array}$ & - & - & - & - \\
\hline $\begin{array}{l}\text { Woman's educational level } \\
\text { (secondary and above) }\end{array}$ & 1.257 & 0.004 & 1.172 & 0.046 \\
\hline $\begin{array}{l}\text { Husband's educational level (ref. non } \\
\text { educated) }\end{array}$ & - & - & - & - \\
\hline $\begin{array}{l}\text { Husband's educational level (primary } \\
\text { or preparatory) }\end{array}$ & 1.178 & 0.025 & 1.118 & 0.176 \\
\hline $\begin{array}{l}\text { Husband's educational level } \\
\text { (secondary and higher) }\end{array}$ & 1.205 & 0.007 & 1.140 & 0.207 \\
\hline $\begin{array}{l}\text { Husband's approval on Family } \\
\text { planning (ref. No) }\end{array}$ & - & - & - & - \\
\hline $\begin{array}{l}\text { Husband's approval on Family } \\
\text { planning (Yes) }\end{array}$ & 3.327 & 0.000 & - & - \\
\hline $\begin{array}{l}\text { Discussion with husband about } \\
\text { Family planning (ref. No) }\end{array}$ & - & & & \\
\hline $\begin{array}{l}\text { Discussion with husband about } \\
\text { Family planning (Yes) }\end{array}$ & 1.693 & 0.000 & & \\
\hline \multicolumn{5}{|l|}{ Context - level variables } \\
\hline $\begin{array}{l}\text { Mean number of children ever born } \\
\text { (centered) }\end{array}$ & 0.624 & 0.000 & 0.500 & 0.000 \\
\hline Mean level of wealth (centered) & 0.737 & 0.007 & 1.000 & 0.001 \\
\hline \multicolumn{5}{|l|}{ Random Effects } \\
\hline Second level variance & 0.069 & .004 & 0.068 & 0.001 \\
\hline Corrected model & $\begin{array}{l}\mathrm{F}=34.519 \\
\text { (d.f. }=9,8384)\end{array}$ & 0.000 & $\begin{array}{l}\mathrm{F}=21.347 \\
(\mathrm{~d} . \mathrm{f} .=8,10798)\end{array}$ & 0.000 \\
\hline
\end{tabular}

Results in the lower panel of Table 2 (Random Effects) show that, after considering the most important contextual predictors, the regional effect on the odds of using any modern contraceptive method reduced by $98.6 \%$ in 2000 and 
2014. In other words, these two final models almost explained to a very high extent the regional effect on our variable of interest; the current use of any modern contraceptive method.

The intercept estimates implies that about $40 \%$ of women in an average region (where the mean wealth index equals the overall mean, the mean number of children equals the overall mean and $U_{0 j}=0$ ) are currently using any modern contraceptive method in 2000 controlling for all woman-level predictors included in the model, while this percentage is $53 \%$ in 2014 . This result suggests that women in an average community are less likely to use any modern method but this result inverted in 2014, as women in an average community are more likely to use any modern method.

We can notice that the number of children ever born and the difference in age between spouses are significant determinants of the current use of any modern contraceptive method both in 2000 and 2014, in an average community and after controlling for all other variables in the model. Still their effects on the outcome variable are very weak as the odds ratio is near 1 .

As for the educational level of women, it has a significant effect on the outcome variable both in 2000 and 2014. Its effects in 2000 and 2014 are consistent since the results show that an increased level of education yields an increased odds of using any modern contraceptive method in an average community and after controlling for all other variables in the model. Its effect in 2000 are stronger than its effect in 2014, women with secondary and higher level of education are 1.25 times likely to use any modern contraceptive method if compared with women with below secondary level of education, while in 2014, women with secondary and higher level of education are 1.17 times likely to use any modern contraceptive method if compared with women with below secondary level of education, controlling for all other predictors in the models and this is for women in an average community.

The results show an important fact that the effect of social characteristics approximated with the educational level of women and husband become insignificant and very weak in 2014 if compared with 2000.

The educational level of husbands has statistically significant effect on the outcome variable in 2000 but it become insignificant in 2014. In 2000, women whose husbands' educational level is 1.2 times likely to use any modern contraceptive method if compared with women whose husbands are illiterate.

Husbands' approval on family planning, FP, is a very important determinant in 2000 since it has a significant effect on the outcome variable. Whenever husbands approve FP, women are 3.3 times likely to use any modern contraceptive method if compared to women whose husbands don't approve in an average community and after controlling the effect of rest of variables included in the model. The same result can be drawn for the discussion of FP with husbands, it has a significant effect on the outcome variable and when the discussion on FP holds between spouses, this yields to an increased odds (odds ratio $=1.69$ ) for using any modern contraceptive method. 
Unfortunately, the last two important determinants; husband's approval on FP and discussion with husband on FP, are not measured in 2014, so that their effect can't be measured and compared between the two time points.

Considering the results of the context level variables, it can be noticed that both the fertility level of the community approximated by the mean number of children ever born and the extent of socio-economic development approximated by the mean level of wealth index have significant effects on the odds of using any modern contraceptive method. As for the mean number of children ever born, when this variable is away from the overall mean by one standard deviation, the odds of using any modern contraceptive method decrease to be 0.624 in 2000 and 0.5 in 2014 for women in an average community. The effect of fertility level of the community become clearer in 2014 if compared with its effect in 2000.

Whenever the mean level of wealth index is one standard deviation away from the overall mean of wealth index, this implies decreased odds for using any modern method in 2000, this effect become trivial in 2014 as the odds ratio equals 1. This means that women living in communities above average level of wealth have the same odds of using any modern contraceptive use as women living in a below average level of wealth.

Finally, $U_{0 j}$ are estimated for each community $j$ both for the null and the final model. Each $U_{0 j}$ represents the effect of community $j$ on the odds of using any modern contraceptive method controlling for all predictors. For the null model in 2000, the highest odds of using are for urban Kalyoubia, while the least odds are for rural Assuit. For the final model, the highest odds are for rural Beheira and the least odds are in rural Assuit again. While in 2014, the highest odds of using is for urban Kalyoubia, while the least odds is for rural Sohag. For the final model, the highest odds of using is for urban Kalyoubia, while the least odds is for rural Sohag. For the final model, the highest odds are for rural Menoufia and the lowest odds are for rural Redsea.

\section{Discussion}

Egypt has one of the successful family planning programs. In spite of the continuous efforts of the family planning program in Egypt, the contraceptive use rate has witnessed a frustrating plateau during 2005 and 2008; to about $60 \%$, and it has slightly decreased in 2014 to 59\%. This stagnation in the prevalence rate of contraceptives during the nineties and the slight decrease experienced during 2008 and 2014 should be investigated through identifying the determinants of using any modern contraceptive method though a multilevel analysis approach. The multilevel analysis is justified through the descriptive analysis which showed that Rural Upper Egypt is the most disadvantaged among others with least prevalence of modern methods over the whole time span (from 2000 to 2014), this is besides previous study of Giusti and Vignoli in 2006, and the hierarchical style of the EDHS data which supports the application.

This study aims at tracking the change in the combination of factors affecting the contraceptive use rate in Egypt between 2000 and 2014, this has been achieved 
through; first, measuring the community effect on the odds of using any modern contraceptive method among currently married women aged (15-49), not pregnant and want no more children (either for spacing or limiting). Second, studying women-level and contextual-level factors that are influencing the odds of using any modern contraceptive method.

From the analysis, It may be concluded that a considerable share of the variability in the log odds of using a modern contraceptive method is due to the differences between communities (higher level units), and this variability doesn't vanish through 2000 and 2014. This indicates that in spite of achieving some of the most important mellinium development goals and the continous development that Egypt achieved regards its population and their charateristics, still we have inequality in the utilization of certain health services. This is not only due to lack or uneven distribution of services, but also this is due to the heterogeniety in the human behaviour, that is due to the context effect on their culture, values and norms.

Adding woman - level predictors to the models (number of children ever born, difference in age between spouses, the educational level of woman and her husband, the attitudes of husband towards family planning, and the discussion between spouses on family planning), the regional effect on the odds of using any modern contraceptive method reduced by $35.6 \%$ in 2000 and $22.7 \%$ in 2014 . The smaller decrease appeared in 2014 model indicates that the women - level characteristics couldn't explain the same share in regional effect as in 2000, this means that the behavior of women in Egypt in 2014 is more influenced by the attitudes and behaviors dominant in contexts around them.

The two final models; where the community - level variables added (level of fertility approximated by mean number of children ever born and the economic level of the community approximated with mean wealth score) explained to a very high extent the regional effect on our variable of interest both in 2000 and 2014. This result agree with the results of Giusti and Vignoli in 2006 and Dias and de Oliveira in 2015, as they have showed that wealth index, as a proxy of the regions' degree of modernization, is responsible for a large amount of the probability of ever use of any contraceptive method. The results indicate also that, in contexts where the norm is for high fertility rates, women behavior is highly influenced towards not using any modern contraceptive method in spite of their need for using which can be deduced through their fertility preferences.

Further analysis are needed to explore the differential strength between some woman - level predictors and contraceptive use through more complex multilevel random intercept and random slope models.

\section{Conclusion}

Rural Upper Egypt is the most disadvantaged among other regions of Egypt with least prevalence of modern methods over the period from 2000 to 2014 . A considerable share of the variability in the odds of using a modern contraceptive 
method is due to the differences between communities (higher level units), and this variability doesn't vanish through 2000 and 2014.

The behavior of women in Egypt in 2014 is more influenced by the attitudes and behaviors dominant in contexts surrounding them. This is concluded through the smaller decrease in ICC appeared in 2014 model after adjusting for womenlevel characteristics if compared to that in 2000.

The effect of social characteristics approximated with the educational level of women and her husband become insignificant and very weak in 2014 if compared with 2000. The wealth index, which acts as a proxy of the regions' degree of modernization, is responsible for a large amount of the probability of the current use of any modern contraceptive method among the study sample.

It may be concluded also that, in contexts where the norm is for high fertility rates, women behavior is highly influenced towards not using any modern contraceptive method in spite of their need for using deduced from their fertility preferences.

\section{References}

Ahmed S, Li Q, Liu L, Tsui AO (2012) Maternal deaths averted by contraceptive use: an analysis of 172 countries. The Lancet 380(9837): 11-125.

Aizenman DE (1988) Impact of family planning on maternal-child health. The future of humanity depends on our children. Profamilia: Planificación, Población y Desarollo 4(13): 28-33.

Al Riyami A, Afifi M, Mabry RM (2004) Women's autonomy, education and employment in Oman and their influence on contraceptive use. Reproductive Health Matters 12(23):144-154.

Awadalla HI (2012) Contraception use among Egyptian women: results from Egypt demographic and health survey in 2005. Journal of Reproduction \& Infertility 13(3): 167-173.

Bongaarts J (1982) The fertility-inhibiting effects of the intermediate fertility variables. Studies in Family Planning 13(6/7):179-189.

Bongaarts J (1984) A simple method for estimating the contraceptive prevalence required to reach a fertility target. Studies in Family Planning 15(4): 184-190.

Dias JG, de Oliveira IT (2015) Multilevel effects of wealth on women's contraceptive use in Mozambique. PLoS One 10(3): e0121758.

Elfstrom KM, Stephenson R (2012) The role of place in shaping contraceptive use among women in Africa. PloS One 7(7): e40670.

El-Moselhy EA, Moftah FM, Darwish MM, Abo-Rahma AH (2017) Trends and determinants of contraceptive use among young (15-24 year) married women: a secondary analysis based on the 2008 and 2014 Egypt Demographic and Health Surveys. The Egyptian Journal of Hospital Medicine 31(4075):1-18.

Eltomy EM, Saboula NE, Hussein AA (2013) Barriers affecting utilization of family planning services among rural Egyptian women. East Mediterr Health Journal 19(5): 400-408.

El-Zanaty F, Way A (2005) Egypt Demographic and Health Survey. Ministry of Health and Macro International: Cairo, Egypt.

El-Zanaty F, Way A (2008) Egypt Demographic and Health Survey. Ministry of Health and Macro International: Cairo, Egypt. 
Entwisle B, Mason WM, Hermalin AI (1986) The multilevel dependence of contraceptive use on socioeconomic development and family planning program strength. Demography 23(2):199-216.

Giusti C, Vignoli D (2006) Determinants of contraceptive use in Egypt: a multilevel approach. Statistical Methods and Applications 15(1): 89-106.

Heck RH, Thomas S, Tabata L (2013) Multilevel Modeling of Categorical Outcomes Using IBM SPSS. UK: Routledge.

Hox JJ, Moerbeek M, Van de Schoot R (2017) Multilevel Analysis: Techniques and Applications. UK: Routledge.

Lamidi EO (2015) State variations in women's socioeconomic status and use of modern contraceptives in Nigeria. PloS one 10(8): e0135172.

Longwe A, Huisman J, Smits J (2012) Effects of knowledge, acceptance and use of contraceptives on household wealth in 26 African countries. African Journal of Reproductive Health 14(4): 17-26.

Mahran M, El-Zanaty FH, Way AA (1995) Perspectives on fertility and family planning in Egypt. Results of further analysis of the 1992 Egypt Demographic and Health Survey.

Ministry of Health and Population, El-Zanaty, Associates and ICF International (2015) Egypt Demographic and Health Survey 2014. Cairo, Egypt and Rockville, Maryland, USA.

Moursund A, Kravdal Ø (2003) Individual and community effects of women's education and autonomy on contraceptive use in India. Population Studies 57(3): 285-301.

Osmani AK, Reyer JA, Osmani AR, Hamajima N (2015) Factors influencing contraceptive use among women in Afghanistan: secondary analysis of Afghanistan Health Survey 2012. Nagoya Journal of Medical Science 77(4): 551-561.

Ragab WS, AbdelWahid WY (2014) Contraception Use among Parous Egyptian Women Attending an Antenatal Clinic. Med J Cairo Univ 82(2): 47-53.

Rashad H, Zaky H (2013) A comparative analysis of fertility plateau in Egypt, Syria and Jordan: policy implications. Cairo: Social Research Center, American University in Cairo.

Raudenbush SW, Bryk AS (2002). Hierarchical Linear Models: Applications and Data Analysis Methods (Vol. 1), Sage.

Samari G (2017) Women's Empowerment and Contraceptive Method Use in Egypt. PRC Research Brief Series.

Sayed HA, Osman MI, El-Zanaty F, Way A (1988) Egypt Demographic and Health Survey. Egypt National Population Council and Institute for Resource Development/ Macro Systems.

Sedgh G, Ashford LS, Hussain R (2016) Unmet need for contraception in developing countries: examining Women's reasons for not using a method. New York: Guttmacher Institute 2: 2015-2016.

Stephenson R, Baschieri A, Clements S, Hennink M, Madise N (2007) Contextual influences on modern contraceptive use in sub-Saharan Africa. American Journal of Public Health 97(7): 1233-1240.

Stephenson R, Beke A, Tshibangu D (2008) Community and health facility influences on contraceptive method choice in the Eastern Cape, South Africa. International Family Planning Perspectives 34(2):62-70.

Stover J, Ross J (2009) How Contraceptive Use Affects Maternal Mortality. USA: Uni ted States agency for international development (USAID). 
